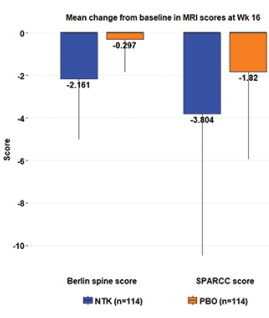

Figure 1. Change from baseline in MRI scores

Disclosure of Interests: Alexander Smirnov: None declared, Inna Gaydukova Grant/research support from: JSC BIOCAD, Speakers bureau: paiment from Pfizer, Novartis, Abbvie, Biocad, Selgene, MSD, Sanofy does not exceed 10000 euros, V Mazurov Grant/research support from: JSC BIOCAD, Shandor Erdes Grant/research support from: JSC BIOCAD, Speakers bureau: JSC BIOCAD, Tatiana Dubinina: None declared, Olga Nesmeyanova Grant/research support from: JSC BIOCAD, Elena llivanova Grant/research support from: JSC BIOCAD, Alena Kundzer: None declared, Nikolaj Soroka: None declared, Anna Eremeeva Grant/research support from: JSC BIOCAD, Ekaterina Chernyaeva Employee of: JSC BIOCAD, Roman Ivanov Employee of: JSC BIOCAD

DOI: 10.1136/annrheumdis-2019-eular.7123

\section{FRI0413 EFFICACY, PHARMACOKINETICS, SAFETY AND IMMUNOGENICITY OF THE BIOSIMILAR HS016 IN COMPARISON WITH ADALIMUMAB IN CHINESE PATIENTS WITH ANKYLOSING SPONDYLITIS: A MULTICENTER, RANDOMIZED, DOUBLE-BLIND, PARALLEL-GROUP, PHASE 3 TRIAL}

Jinmei Su, LI Mengtao, Xiaofeng Zeng. Peking Union Medical College Hospital, Bejing, China

Background: HS016, a proposed biosimilar to adalimumab, has an identical amino acid sequence, similar physicochemical and in vitro functional properties to adalimumab originator.

Objectives: To assess the efficacy, pharmacokinetic (PK) equivalence, safety and immunogenicity of HS016 compared with adalimumab in Chinese patients with ankylosing spondylitis (AS).

Methods: In a multicenter, randomized, double-blind, parallel-controlled phase 3 study, patients with AS fulfilled with the Modified New York Criteria in 1984 in China were randomized 2:1 to receive HS016 or adalimumab with a dose of $40 \mathrm{mg}$ every other week for 24 weeks. Blood samples for PK analyses were collected in about half of AS patients pre-dose every other week and during week 12 and week 14. Samples for anti-drug antibodies (ADA) and neutralizing antibodies (NAb) were analyzed in all patients. The primary endpoint was the proportion of patients achieving 20\% improvement in Assessment in SpondyloArthritis International Society (ASAS 20) at week 24. Equivalent efficacy was concluded if $90 \%$ confidence interval (Cl) of the difference in ASAS 20 response rate was between $-15 \%$ and $15 \%$. The secondary endpoints included the ASAS 20 response rate at week 12, ASAS 40, 50\% improvement in Bath Ankylosing Spondylitis Disease Activity Index (BASDAI 50), ASAS5/6 response rate at week 12 and week 24, PK, safety and immunogenicity.

Results: 416 patients were randomly assigned to receive HS016 and 232 to receive adalimumab. The ASAS 20 response rates at week 24 were $87.50 \%$ and $90.09 \%$ in HS016 and adalimumab groups, respectively, and the difference was $-2.59 \%(90 \% \mathrm{Cl},-6.77 \%$ to $1.60 \%)$, demonstrating clinical equivalence between HS016 and adalimumab. No significant difference of the proportion of ASAS 40, BASDAI 50 and ASAS $5 / 6$ between the two groups were detected at week 12 or week 24 (table 1).

Table 1. Response rates (\%) at week 12 and week 24.

\begin{tabular}{lcccccc}
\hline \multicolumn{3}{c}{ Week 12 } & & Week 24 & \\
\hline & HS016 & Adalimumab & $\mathrm{P}$ & HS016 & Adalimumab & $\mathrm{P}$ \\
& $(\mathrm{N}=416)$ & $(\mathrm{N}=232)$ & value & $(\mathrm{N}=416)$ & $(\mathrm{N}=232)$ & value \\
ASAS 20 & 79.57 & 81.03 & 0.65 & 87.50 & 90.09 & 0.32 \\
ASAS 40 & 58.65 & 61.64 & 0.35 & 71.15 & 75.43 & 0.18 \\
BASDAI & 61.78 & 61.21 & 0.96 & 76.44 & 78.45 & 0.52 \\
50 & & & & & & \\
ASAS 5/6 & 57.45 & 58.62 & 0.86 & 62.98 & 67.24 & 0.37 \\
\hline ASAS, the Assessment in Spondylorthritis
\end{tabular}

ASAS, the Assessment in SpondyloArthritis International Society; BASDAI, Bath Ankylosing

Spondylitis Disease Activity Index.
Pharmacokinetic values from 188 AS patients in HS016 group and 109 in adalimumab group were analyzed. The geometric means for steadystate maximum plasma concentration $\left(\mathrm{C}_{\max }\right)$ and area under the plasma concentration-time curve from time zero to infinity $\left(A \cup C_{\text {inf }}\right)$ were similar between HS016 group and adalimumab group. The proportions of treatment-emergent adverse events, serious adverse events and injection site reactions were similar between the two groups (table 2).Table 2. Adverse events in AS patients with HS016 or adalimumab.

\begin{tabular}{lcc}
\hline $\begin{array}{l}\text { Adverse events } \\
\mathrm{N}(\%)\end{array}$ & $\begin{array}{c}\mathrm{HS} 016 \\
(\mathrm{~N}=416)\end{array}$ & $\begin{array}{c}\text { Adalimumab } \\
(\mathrm{N}=232)\end{array}$ \\
\hline TEAEs & $352(84.62)$ & $200(86.21)$ \\
TEAEs related to study drug & $267(64.18)$ & $154(66.38)$ \\
TEAEs leading to discontinuation & $22(5.29)$ & $15(6.47)$ \\
SAEs & $18(4.33)$ & $6(2.59)$ \\
Injection site reactions & $21(5.05)$ & $11(4.74)$ \\
\hline
\end{tabular}

TEAE, treatment-emergent adverse event; SAE, serious adverse event.

The frequencies of $\mathrm{ADA}$ and $\mathrm{NAb}$ positive were similar between the two groups at different time points. Through week $24,79.13 \%$ of 412 patients in HS016 and $79.91 \%$ of 229 patients in adalimumab group developed ADAs, and $17.48 \%$ of 412 in HS016 and $18.78 \%$ of 229 in adalimumab group developed NAbs.

Conclusion: The results of efficacy, PK, safety, immunogenicity from the study conducted in Chinese AS patients support a high similarity between HS016 and the adalimumab.

Acknowledgement: In addition to Peking Union Medical College Hospital, another 27 sites from China were also involved in the study. The authors thank the investigators who made the study possible.

Disclosure of Interests: None declared

DOI: 10.1136/annrheumdis-2019-eular.3433

\section{\begin{tabular}{|l|l}
\hline FRI0414 SECUKINUMAB PROVIDES RAPID AND SIGNIFICANT \\
\hline
\end{tabular} IMPROVEMENT IN THE SIGNS AND SYMPTOMS OF ANKYLOSING SPONDYLITIS: PRIMARY (16-WEEK) RESULTS FROM A PHASE 3 CHINA-CENTRIC STUDY, MEASURE 5}

Feng Huang ${ }^{1}$, Fei Sun ${ }^{1}$, Weiguo Wan ${ }^{2}$, Lijun $\mathrm{Wu}^{3}$, Lingli Dong ${ }^{4}$, Xiao Zhang ${ }^{5}$, TaeHwan Kim ${ }^{6}$, Raj Sengupta ${ }^{7}$, Ladislav Šenolt ${ }^{8}$, Yi Wang $^{9}$, Haomin Qiu ${ }^{10}$, Brian Porter ${ }^{9}$, Sibylle Haemmerle ${ }^{11} .{ }^{1}$ Chinese PLA General Hospital, Beijing, China; ${ }^{2}$ Fudan University, Shanghai, China; ${ }^{3}$ People's Hospital of Xinjiang Uygur Autonomous Region, Urumqi, China; ${ }^{4}$ Tongji Medical College of Huazhong University of Science andTechnology, Wuhan, China; ${ }^{5}$ Guangdong General Hospital, Guangzhou, China; ${ }^{6}$ Hanyang University Hospital for Rheumatic Diseases, Seoul, Korea, Rep. of (South Korea); ${ }^{7}$ Royal National Hospital for Rheumatic Disease, Bath, United Kingdom; ${ }^{8}$ Institute of Rheumatology, Prague, Czech Republic; ${ }^{9}$ Novartis Pharmaceuticals Corporation, East Hanover, United States of America; ${ }^{10}$ China Novartis Institutes for Biomedical Research, Shanghai, China; ${ }^{11}$ Novartis Pharma AG, Basel, Switzerland

Background: Secukinumab (SEC), a fully human monoclonal antibody to IL-17A, has demonstrated significant and sustained efficacy in patients (pts) with ankylosing spondylitis (AS) across several phase 3 studies. ${ }^{1-3}$ MEASURE 5 (NCT02896127) is a placebo (PBO)-controlled phase 3 China centric 1-year study in pts with active AS.

Objectives: To present the primary efficacy and safety results of the MEASURE 5 study.

Methods: Pts were randomised (2:1) to receive subcutaneous (s.c.) SEC $150 \mathrm{mg}$ or PBO at baseline (BL), Weeks (Wks) 1, 2, 3, and 4, and then every 4 wks $(q 4 w)$ thereafter through Wk 52 . All PBO pts were switched to s.c. SEC $150 \mathrm{mg} \mathrm{q} 4 \mathrm{w}$ starting at Wk 16. Primary endpoint was ASAS20 at Wk 16. Key secondary endpoints were ASAS40, hsCRP, ASAS5/6, BASDAI, SF-36 PCS, ASQoL and ASAS partial remission (PR). Randomisation was stratified by geographic location (China vs. nonChina). Statistical analyses used non-responder imputation (NRI) for binary and mixed-effect model repeated measures (MMRM) for continuous variables. A pre-defined hierarchical testing strategy was used for overall population to adjust multiplicity. Safety analysis included all pts who received $\geq 1$ dose of SEC.

Results: A total of 458 pts were randomised; 327 (71.4\%) from China and 131 (28.6\%) from Czech Republic, South Korea and UK. Overall, $97.7 \%(298 / 305)$ and $97.4 \%(149 / 153)$ pts in the SEC and PBO groups, respectively, completed 16 wks. BL characteristics were comparable between groups. Approximately $24 \%$ of pts were anti-TNF-inadequate responders/intolerant. The primary endpoint was met; SEC (58.4\%) significantly improved ASAS20 response at Wk 16 vs. PBO $(36.6 \% ; P<$ $0.0001)$; corresponding rates were $56.0 \%$ vs. $38.5 \%(P<0.01)$ in the Chinese population. Improvements were demonstrated in all secondary 
endpoints at Wk 16 for SEC vs. PBO (overall and Chinese populations; Table). Serious AE rates were reported in $3.3 \%$ and $2.0 \%$ of SEC and PBO pts, respectively. Uveitis was reported in $1.0 \%$ (SEC) and $0.7 \%$ (PBO) of pts. No MACE, IBD or deaths were reported.

Conclusion: SEC demonstrated rapid and significant improvement in the signs and symptoms of AS in both the overall and Chinese populations. Secukinumab was well tolerated with no new safety signals identified.

\section{REFERENCES:}

[1] Baeten D, et al. N Engl J Med. 2015;373:2534-48.

[2] Pavelka K, et al. Arthritis Res Ther. 2017;19:285.

[3] Kivitz AJ, et al. Rheumatol Ther. 2018;5:447-62.

Table. Wk 16 data

\begin{tabular}{|c|c|c|c|c|}
\hline & \multicolumn{2}{|c|}{ Overall } & \multicolumn{2}{|c|}{ Chinese } \\
\hline & $\begin{array}{l}\text { SEC } 150 \mathrm{mg} \\
\quad(\mathrm{N}=305)\end{array}$ & $\begin{array}{c}\text { PBO } \\
(\mathrm{N}=153)\end{array}$ & $\begin{array}{l}\text { SEC } 150 \mathrm{mg} \\
\quad(\mathrm{N}=218)\end{array}$ & $\begin{array}{c}\text { PBO } \\
(\mathrm{N}=109)\end{array}$ \\
\hline ASAS $20^{1}$ & $58.4^{*}$ & 36.6 & $56.0^{\S}$ & 38.5 \\
\hline${\text { ASAS } 40^{1}}^{1}$ & $43.9^{*}$ & 17.0 & $41.7^{*}$ & 16.5 \\
\hline hsCRP ${ }^{2,3}$ & $0.39^{*}$ & 1.05 & $0.33^{*}$ & 0.97 \\
\hline ASAS5/ $6^{1}$ & $47.2^{*}$ & 17.6 & $45.9^{*}$ & 17.4 \\
\hline BASDAI $^{2}$ & $-2.79^{*}$ & -1.50 & $-2.63^{*}$ & -1.37 \\
\hline SF-36 PCS ${ }^{2}$ & $7.43^{*}$ & 4.60 & $7.18^{*}$ & 4.07 \\
\hline $\mathrm{ASQ}^{2}{ }^{2}$ & $-4.83^{*}$ & -2.93 & $-4.50^{\dagger}$ & -2.50 \\
\hline ASAS PR ${ }^{1}$ & $16.7^{\S}$ & 6.5 & $15.1^{ \pm}$ & 6.4 \\
\hline \multicolumn{5}{|c|}{$\begin{array}{l}{ }^{\star} P<0.0001 ;{ }^{\dagger} P<0.001 ;{ }^{\S} P<0.01 ;{ }^{\ddagger} P<0.05 \text { vs. PBO ( } P \text {-values are adjusted for overall } \\
\text { and un-adjusted for Chinese populations). NRI for binary and MMRM for continuous } \\
\text { variables. } \\
{ }^{1} \% \text { responders; }{ }^{2} \text { LS mean change from BL; }{ }^{3} \text { ratio of post-BL/BL; LS, least squares; N, tota } \\
\text { number of randomised pts }\end{array}$} \\
\hline
\end{tabular}

Disclosure of Interests: Feng Huang: None declared, Fei Sun: None declared, Weiguo Wan: None declared, Lijun Wu: None declared, Lingli Dong: None declared, Xiao Zhang: None declared, Tae-hwan Kim: None declared, Raj Sengupta Grant/research support from: AbbVie, Celgene Corporation, Merck Sharp \& Dohme, Novartis, Pfizer, and UCB, Speakers bureau: AbbVie, Celgene Corporation, Merck Sharp \& Dohme, Novartis, Pfizer, and UCB, Ladislav Šenolt Grant/research support from: AbbVie, Consultant for: AbbVie, Bristol-Myers Squibb, Celgene Corporation, Merck Sharp and Dohme, Novartis, Pfizer, Roche, UCB, Amgen, Takeda, Speakers bureau: AbbVie, Amgen, Bristol-Myers Squibb, Celgene Corporation, Eli Lilly, Merck Sharp and Dohme, Novartis, Pfizer, Roche, UCB, Yi Wang Shareholder of: Novartis, Employee of: Novartis, Haomin Qu Shareholder of: Novartis, Employee of: Novartis, Brian Porter Shareholder of: Novartis, Employee of: Novartis, Sibylle Haemmerle Shareholder of: Novartis, Employee of: Novartis

DOI: 10.1136/annrheumdis-2019-eular.2560

\section{FRI0415 BIOSIMILAR BAT1406 VERSUS ADALIMUMAB THERAPY ON ACTIVE ANKYLOSING SPONDYLITIS: A RANDOMIZED, DOUBLE-BLINDED, MULTICENTER, CONTROLLED PHASE 3 TRIAL}

Liudan Tu ${ }^{1}$, Qiujing Wei ${ }^{1}$, Ya Xie ${ }^{1}$, Guixiu Shi ${ }^{2}$, Huaxiang Liu $^{3}$, Qingchun Huang ${ }^{4}$, Jian $\mathrm{Wu}^{5}$, Zhenchun Zhang ${ }^{6}$, Shuangyan $\mathrm{Cao}^{1}$, Jieruo $\mathrm{Gu}^{1} .{ }^{1}$ the Third Affiliated Hospital of SUN YAT-SEN University, Guangzhou, China; ${ }^{2}$ the First Affiliated Hospital of Xiamen University, Xiamen, China; ${ }^{3}$ QILU Hospital of Shandong University, Shandong, China; ${ }^{4}$ Guangdong Province Traditional Chinese Medical Hospital, Guangzhou, China; ${ }^{5}$ the First Affiliated Hospital of SOOCHOW University, Suzhou, China; ${ }^{6}$ Linyi City People Hospital, Shandong, China

Background: Adalimumab has been proved to be effective and safety in management of ankylosing spondylitis (AS) in several clinical trials. In China, small proportion of AS patients had ever used TNF inhibitors and most of them discontinued because of expensive cost. BAT1406 and ADA have demonstrated comparable in protein structure, physicochemical properties, biological activity and immunological characteristics.

Objectives: To compare the effects, safety and immunogenicity of biosimilar BAT1406 vs adalimumab (ADA) in patients with active AS.
Methods: A multicenter, randomized, non-inferiority, double-blinded, ADA controlled clinical trial with 24 weeks of follow-up was conducted in China. Participants with active AS defined as BASDAI $\geq 4$ and average back pain score (VAS 0-10) $\geq 4$ were eligible for participation. Participants were randomly assigned to receive BAT1406 (40mg q2w) or adalimumab (40mg q2w) at a ratio of $2: 1$ for 24 weeks. Primary outcome was the proportion of patients achieving ASAS20 response at 12 weeks. Inclusion of the $95 \% \mathrm{Cl}$ of the ASAS20 response difference within a $\pm 15 \%$ margin was required for equivalence. Secondary outcomes included ASAS40, ASAS5/6, BASDAI50 response, patient reported outcomes, safety and immunogenicity. This trial is approved by China Food and Drug Administration (number 2015L05751)

Results: 554 eligible patients were enrolled from Jan 2017 to Aug 2017 and randomly assigned to receive BAT1406 $(n=363)$ or Adalimumab ( $n=191)$ participants, 514 completed the study. Patients $(86.5 \%$ of whom were male and whose mean age was 31.6 years) had a mean disease duration was 5.82 years. Over 12 weeks, $75.69 \%$ of patients in BAT1406 group and $73.68 \%$ in ADA group (between group difference 1.6\%, 95\% Cl $[-6.82 \%$ to $10.03 \%]$ ) achieved ASAS20 response (per-protocol set; adjusted treatment difference $2.16 \%, 95 \% \mathrm{Cl}[-6.9 \%$ to $11.22 \%])$. Outcomes for secondary end points were consistent with the primary efficacy findings. The frequency of adverse events (AEs) was comparable between groups ((BAT1406 316[87.1\%] vs ADA 162 [85.3\%]), as well as serious AEs, adverse drug reactions and discontinuations due to AEs. Similar positive rate was found in two groups for anti-drug antibodies up to week 24

Conclusion: The study met the primary endpoint of demonstrating equivalent efficacy of BAT1406 and ADA. BAT1406 was comparable in toler ance, safety and immunogenicity with ADA in active AS patients.

\section{REFERENCES}

[1] Park W, Yoo DH, Miranda P, et al. Efficacy and safety of switching from reference infliximab to CT-P13 compared with maintenance of CT-P13 in ankylosing spondylitis: 102-week data from the PLANETAS extension study. Annals of the rheumatic diseases. 2017;76(2):346-354.

[2] Park W, Yoo DH, Jaworski J, et al. Comparable long-term efficacy, as assessed by patient-reported outcomes, safety and pharmacokinetics, of CT-P13 and reference infliximab in patients with ankylosing spondylitis: 54-week results from the randomized, parallel-group PLANETAS study. Arthritis research \& therapy. 2016;18:25.

[3] Chingcuanco F, Segal JB, Kim SC, Alexander GC. Bioequivalence of Biosimilar Tumor Necrosis Factor-alpha Inhibitors Compared With Their Reference Biologics: A Systematic Review. Ann Intern Med. 2016;165(8):565574.

[4] Kneepkens EL, Wei JC, Nurmohamed MT, et al. Immunogenicity, adalimumab levels and clinical response in ankylosing spondylitis patients during 24 weeks of follow-up. Annals of the rheumatic diseases. 2015;74(2):396 401.

[5] Kanters TA, Stevanovic J, Huys I, Vulto AG, Simoens S. Adoption of Biosimilar Infliximab for Rheumatoid Arthritis, Ankylosing Spondylitis, and Inflammatory Bowel Diseases in the EU5: A Budget Impact Analysis Using a Delphi Panel. Front Pharmacol. 2017;8:322.

Acknowledgement: The authors wish to thank the patients and study personnel who made this trial possible, and the study investigators: Hongsheng Sun (Department of Rheumatology, Shandong Provincial Hospital), Dan Wang (Wuhan Puai Hospital), Xiaoxia Wang (the Second Hospital of Shanxi Medical University), Zhenyu Jiang (the First Hospital of JILIN University), Liqi $\mathrm{Bi}$ (the China-Japan Union Hospital of JILIN University), Yanhong Huang (Beijing Jishuitan Hospital), Ju Liu (JiuJiang NO.1 People's Hospital), Xiaomei Li (Anhui Provincial Hospital), Hao Zhang (the Third Xiangya Hospital of Central South University), Cibo Huang (Beijing Hospital), Longxin Ma (Yancheng City NO.1 People's Hospital), Yonghong Zhang (Luoyang Orthopedic Hospital), Zhijun Li (the First affiliated hospita of Bengbu Medical College), Chenghui Huang (the Second Affiliated hospital of Guangzhou Medical University), Lin Chen (Jinlin Province People's Hospital), Junsong Li (Daqing Oilfield General Hospital), Xiumei Liu (the First Affiliated Hospital of Shanxi Medical University).

Disclosure of Interests: None declared

DOI: 10.1136/annrheumdis-2019-eular.4455 